\title{
INCIDÊNCIA DE DISTÚRBIOS MUSCULOESQUELÉTICOS EM POLICIAIS MILITARES PELO IMPACTO DO USO DE COLETE BALÍSTICO
}

\author{
Diego Rodrigues Pessoa ${ }^{1}$ \\ Aureny da Gama Dionísio² \\ Lívia Danyelle Viana Lima ${ }^{3}$ \\ Rosana Maria Nogueira Gonçalves Soares ${ }^{4}$ \\ Janaína de Moraes Silva ${ }^{5}$
}

Resumo: As lesões por esforço repetitivo (LER) representam um grande problema para a saúde pública. Este trabalho tem como objetivo, analisar a prevalência de distúrbios osteomusculares em policiais militares. O estudo trata-se de uma pesquisa do tipo observacional, transversal de caráter descritivo, participaram da pesquisa 26 policiais militares do sexo masculino, foram submetidos à aplicação dos questionários Nórdico de Sintomas Osteomusculares e do índice de Oswestry para Avaliação da Dor. Os resultados apontam que os maiores índices de dor musculoesquelética prevaleceram na região da coluna dorsal e lombar e na região do pescoço, já em relação ao índice de Oswestry foi constatado que 30\% da amostra sentiram dor em nível moderado. O uso diário do colete balístico por policiais militares pode ocasionar distúrbios osteomusculares, bem como desencadear dor, mesmo não sendo fator de limitação funcional grave para desempenho das atividades diárias.

Palavras-chave: Policiais Militares; Colete Balístico; Colete à Prova de Bala; Distúrbio Osteomusculares.

\footnotetext{
1 Centro de Laserterapia e Fotobiologia - CELAFO/ Instituto de Pesquisa e Desenvolvimento Universidade do Vale do Paraíba (UNIVAP), Brasil. E-mail: fisio.diegorodrigues@gmail.com.

2 Bacharelado em Fisioterapia/Faculdade Maurício de Nassau, Teresina/PI, Brasil. E-mail: diego.neto@hotmail.com.

3 Bacharelado em Fisioterapia/Faculdade Maurício de Nassau, Teresina/PI, Brasil. E-mail: diegorodriguesperfil12@gmail.com.

${ }^{4}$ Bacharelado em Fisioterapia, Faculdade Santo Agostinho (FSA), Brasil. E-mail: rosanameireles@gmail.com.

${ }^{5}$ Centro de Ciências da Saúde-CCS, Universidade Estadual do Piauí, Brasil. E-mail: fisiojanainams@gmail.com.
} 